Received: 2018.12.06 Accepted: 2019.02.12 Published: 2019.05 .01

\section{Chromophobe Renal Cell Carcinoma Presenting as a Cystic Renal Mass: Case Report and Review of the Literature}

Department of Radiology, Prince Sultan Military Medical City, Riyadh, Saudi Arabia
Authors' Contribution:

Study Design A

Data Collection B

Statistical Analysis C

Data Interpretation D

Manuscript Preparation E

Literature Search $F$

Funds Collection G
AEF Maram H. AlGhamdi

BG Nayef A. AlShabyli

ABCG Abdullah Alayed
Corresponding Author: Conflict of interest:
Maram H. AlGhamdi, e-mail: mhalghamdi@hotmail.com

None declared

\begin{tabular}{|c|c|}
\hline Patient: & Male, 28 \\
\hline Final Diagnosis: & Cystic chromophobe rcc \\
\hline Symptoms: & Flank pain \\
\hline Medication: & - \\
\hline inical Procedure: & Ct scan \\
\hline Specialty: & Radiology \\
\hline Objective: & Rare disease \\
\hline Background: & $\begin{array}{l}\text { Chromophobe renal cell carcinoma is a rare subtype of renal cell carcinoma which accounts for } 4 \% \text { to } 6 \% \text { of } \\
\text { renal cell carcinoma subtypes. These tumors generally have a good prognosis. Typical radiological features in- } \\
\text { clude a well-defined homogeneous mass and a hypo-vascular soft tissue enhancement. Cystic chromophobe re- } \\
\text { nal cell carcinoma is a very rare entity in which the overall estimated cystic renal cell carcinoma of all subtypes } \\
\text { account for } 4 \% \text {. We describe a rare presentation of chromophobe renal cell carcinoma presenting as a uniloc- } \\
\text { ular cystic mass with mural nodules. }\end{array}$ \\
\hline Case Report: & $\begin{array}{l}\text { A 28-year-old healthy male presented with a history of right upper quadrant fullness and discomfort. Hepatomegaly } \\
\text { was expected on examination. Ultrasonographic assessment revealed a normal liver size and echo texture. } \\
\text { However, a large cystic mass measuring } 15.7 \times 12.8 \mathrm{~cm} \text { was found arising from the right kidney which showed no } \\
\text { internal vascularity but turbid fluid and debris within the dependent regions of the mass. Multiphase computed } \\
\text { tomography scan showed a large unilocular cystic mass with enhancing mural nodules. There was no lympho- } \\
\text { vascular or peri-renal invasion. The patient underwent uneventful total right renal nephrectomy. Histological } \\
\text { examination revealed a chromophobe renal cell carcinoma of grade II. }\end{array}$ \\
\hline Conclusions: & $\begin{array}{l}\text { Cystic renal neoplasm differential diagnosis varies from benign entities to malignant neoplasms. Knowledge of } \\
\text { the variable common features for each renal cell carcinoma subtypes can aid in narrowing the differential di- } \\
\text { agnosis and prompt appropriate surgical management since a possibility of nephron sparing technique might } \\
\text { still take place in suspected cystic chromophobe renal cell carcinoma but never for cystic clear cell renal cell } \\
\text { carcinoma. }\end{array}$ \\
\hline
\end{tabular}

MeSH Keywords:

MeSH: Adenoma, Chromophobe • Carcinoma, Renal Cell • Kidney Diseases, Cystic

Full-text PDF: https://www.amjcaserep.com/abstract/index/idArt/914465

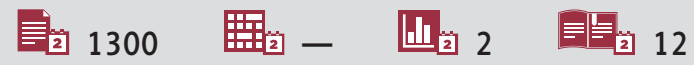




\section{Background}

Chromophobe renal cell carcinoma (crRCC) is a rare subtype of RCC which accounts for $4 \%$ to $6 \%$ of RCC subtypes which are: clear cell RCC, papillary RCC, hereditary cancer syndromes, multilocular cystic RCC, collecting duct carcinoma, medullary carcinoma, mucinous tubular and spindle cell carcinoma, neuroblastoma-associated RCC, Xp11.2 translocation-TFE3 carcinoma, and unclassified lesions [1].

CrRCC arises from the cortical collecting duct, type B intercalated cells and is characterized histologically by its large polygonal pale cells, prominent cell membrane, reticulated cytoplasm, and peri-nuclear halos [1-3]. Sarcomatous degeneration can complicate crRCC in which an aggressive non-typical features would be associated with the tumor both radiologically and histologically [3].

These tumors are commonly of grade I or II at diagnosis and carry a favorable prognosis and an estimated $90 \%$ 5-year survival rate. There is no sex predilection [2,4]. However, crRCC has a known association with Birt Hogg Dobe syndrome, where crRCC can coexist with oncocytoma which is also known as a hybrid tumor [5].

The typical radiological features of crRCC include a hypo-vascular solid tumor with well-defined margins. Necrosis or cystic degeneration have been rarely reported [6]. Central scar as well as a spoke wheel pattern of enhancement on angiography have been described with crRCC, but can also be seen with oncocytoma, which is a benign renal tumor which is believed to share the same origin as crRCC [7].

Cystic RCCs are rare among all RCC subtypes, accounting for only $1 \%$ to $4 \%$ of all RCCs as reported in previous studies [8]. In our case report, we describe a rare presentation of a crRCC that was predominantly cystic with a thick enhancing wall and mural nodules. This rare presentation is believed to account for $4 \%$ of all morphological variants of chromophore RCC $[6,9]$.

\section{Case Report}

A 28-year-old male who had no pre-existing medical condition nor prior surgical history presented to Prince Sultan Military Medical City, Riyadh-Saudi Arabia with a complaint of right upper quadrant discomfort and fullness. No weight loss was reported by the patient. There was no fever or dysuria. The initial laboratory assessment revealed normal complete blood count as well as normal urinalysis and hepatobiliary enzymes values. On physical examination, the examiner reported marked dullness on percussion beyond the normal expected liver span in which hepatomegaly was suspected. The rest of the system review was unremarkable.
The patient underwent initial assessment by ultrasonographic scanning of the upper and lower abdomen. The liver showed normal echo-texture with no masses. The size of the liver was estimated to be $17.7 \mathrm{~cm}$. However, the right kidney was significantly enlarged with an estimated size of $16.2 \mathrm{~cm}$ in the long axis. It appeared to be replaced by a large well-defined cystic mass measuring $15.7 \times 12.8 \mathrm{~cm}$. There was no internal flow vascularity within the cystic mass. Turbid fluid content and debris were noted within the dependent areas of the mass suggesting complex nature. The initial differential diagnosis was complicated cysts such as hematoma, abscess, or cystic renal neoplasm.

Further assessment with computed tomography (CT) scan was obtained in pre-contrast, arterial, porto-venous, and delayed phases. The scan showed a cystic mass arising from the inter-polar region of the right kidney. The mass was measuring $15 \times 15 \times 13 \mathrm{~cm}$. The Hounsfield Units (HU) of the solid component of the cystic mass were compared to those of the renal cortex in the arterial (35 sec),venous (60 sec), and delayed (7 min). These $\mathrm{HU}$ were 74,77 , and $50 \mathrm{HU}$ for the solid components of the cystic mass and 265, 210, and $129 \mathrm{HU}$ for the renal cortex in all phases respectively (Figure 1).

There was no associated extra capsular extension nor vascular invasion. There were no size significant lymph nodes regionally nor distally.

The CT study was the final imaging assessment for the patient and the cystic canal mass was labeled as a Bosniak type IV renal cyst.

The patient underwent a total right nephrectomy with uneventful post-operative period and was discharged on the fourth post-operative day with regular clinical follow-up.

Gross pathological examination of the surgical specimen revealed a uni-focal cystic mass which measured $15 \times 15 \times 13 \mathrm{~cm}$. The maximum wall thickness of the cyst was $0.3 \mathrm{~cm}$. The cystic mass was filled with serous material. There surrounding renal parenchymal tissues were normal.

Histological assessment of the cystic mass showed solid nests and trabeculae, composed of polygonal cells with distinct cell borders. Nuclei were irregular, wrinkled, and angulated with perinuclear halos in a background of pink cytoplasm. Extensive necrosis and cystic changes were present as well, in which all were consistent with chromophobe type RCC (Figure 2). There was no capsular or angiolymphatic invasion. Fuhrman nuclear grading of the mass was consistent with grade 2 and the final TNM stage was T2 NO MO. 


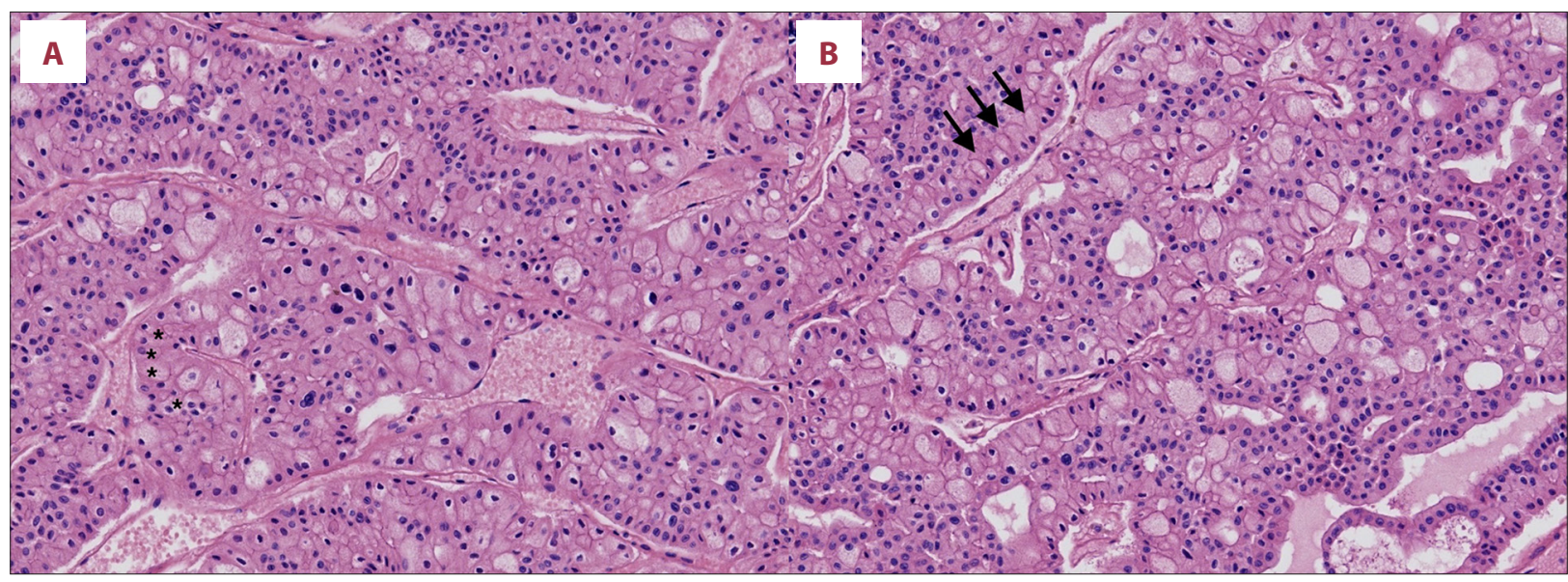

Figure 1. (A, B) Regular hematoxylin and eosin stain showing solid nests and trabecular composed of polygonal cells with distinct cell borders "vegetable cells" (black arrows). Nuclei are irregular, wrinkled, and angulated with perinuclear halos in a background of pink cytoplasm (asterisks). These findings were diagnostic for chromophore renal cell carcinoma.

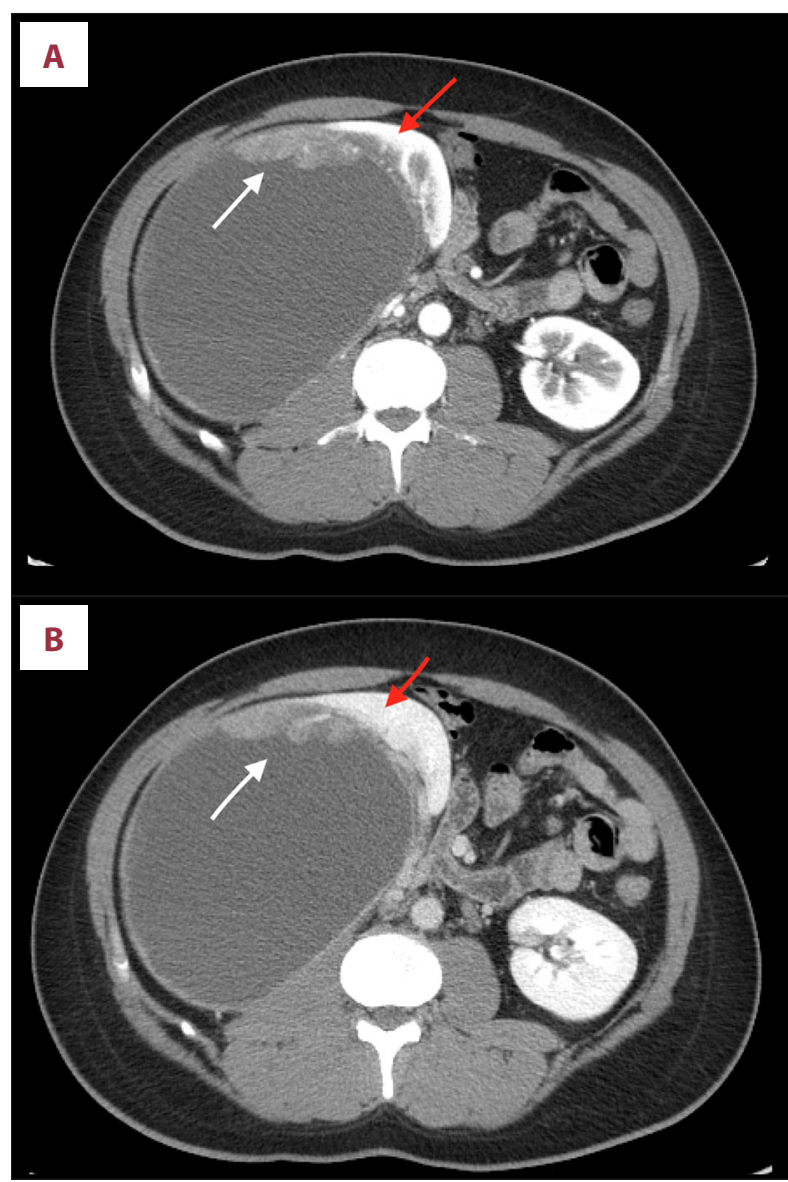

\section{Discussion}

Cystic RCC is a rare entity and chromophobe RCC presenting as a predominantly cystic mass is even a more uncommon presentation $[2,9]$.

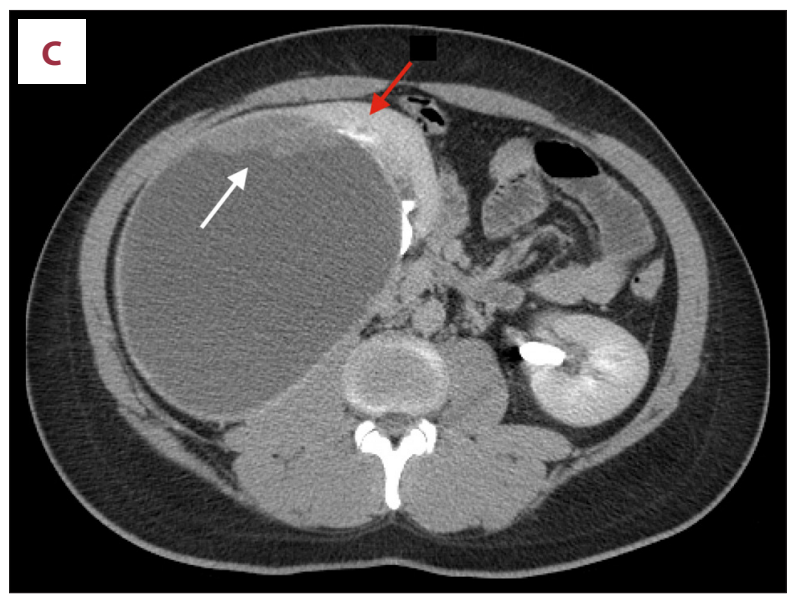

Figure 2. Axial computed tomography scan at the level of the right kidney mass obtained in (A) corticomedullary renal phase, (B) nephrogenic renal phase and delayed phases, and (C) excretory renal phase illustrating the cystic nature of the right renal mass with peripheral enhancing mural nodules (white arrows) which were enhanced less than the normal renal cortex (red arrows) in all phases.

We reviewed one of the largest case series, conducted by Raman et al. (2013) to study the radiological features of crRCC. The study included 35 cases that presented with pathologically proven crRCC at a single institution between 2005 and 2012 [9]. The investigators had studied the variable morphologic features, enhancement characteristics, and clinical outcomes of the crRCC cases. The morphological parameters they studied were divided as follow: $100 \%$ solid, mostly solid with a small cystic component, equally cystic and solid, mostly cystic with a small solid component, or $100 \%$ cystic. Only 1 case out of 35 cases was reported to present as a predominantly cystic mass, which account for $3 \%$ of the study sample [9] indicating the rarity of this presentation. 
A review article by Mugila et al. concluded that the solid part of crRCC is commonly hypo-vascular as compared with the renal cortex, and most of time presents as a moderate contrast uptake (80-100 HU) in the corticomedullary phase [3]. We had a comparable attenuation of values and the enhancing solid component was hypo-vascular compared to the renal cortex in the late-arterial (corticomedullary) phase as well as in the venous (nephrogenic) phase and the delayed (excretory) phase. The HU of the solid component was measured as 74,77 , and $50 \mathrm{HU}$ respectively.

These values were comparable to those from a study by Young et al. who reported attenuation values of 78.5, 89.5, and $63.0 \mathrm{HU}$ in the corticomedullary, nephrographic, and excretory phases, respectively [10].

Another review article of the common RCC subtype features by Low et al. suggested that the presence of a central stellate scar and spoke-wheel enhancement could help in differentiating crRCC from other RCC subtypes, but not from oncocytoma [11]. However, none of these subtype features were present in our patient's case. In our case, there was no perirenal or vascular invasion, and this was consistent with findings of typical features of crRCC described by Low et al., despite the large size of the mass at diagnosis [11].

\section{References:}

1. Eble JN, Sauter G, Epstein JI, Sesterhenn IA (eds.): Pathology and genetics of tumours of the urinary system and male genital organs. Lyon, France, IARC Press, 2004

2. Prasad SR, Humphrey PA, Catena JR et al: Common and uncommon histologic subtypes of renal cell carcinoma: Imaging spectrum with pathologic correlation. Radiographics, 2006; 26: 1795-806; discussion, 1806-10

3. Muglia VF, Prando A: Renal cell carcinoma: Histological classification and correlation with imaging findings. Radiol Bras, 2015; 48: 166-74

4. Cheville JC, Lohse $\mathrm{CM}$, Zincke $\mathrm{H}$ et al: Comparisons of outcome and prognostic features among histologic subtypes of renal cell carcinoma. Am Surg Pathol, 2003; 27: 612-24

5. Prando A, Prando D, Prando P: Renal cell carcinoma: Unusual presentations. Radiographics, 2006; 26: 233-44

6. Murad T, Komaiko W, Oyasu R, Bauer K: Multilocular cystic renal cell carcinoma. Am J Clin Pathol, 1991; 95: 633-37
Flank pain has been reported as the most common presenting symptom (34\%) for patients with crRCC as reported in a crRCC case series of Raman et al. In our case, the patient presented only with right upper quadrant pain and discomfort with otherwise normal laboratory testing values and no macroscopic nor microscopic hematuria [9].

\section{Conclusions}

Our patient's case, along with other cases that studied cystic variants of crRCC, suggests that close observation is an option instead of surgical resection in cases where there is no disease outside the renal capsule and similar patterns of attenuation as described in the literature. However, this was not achievable in our case, due to the symptomatic association of the mass. Knowledge of the variable common features for each RCC subtypes can aid in narrowing the differential diagnosis and prompt appropriate surgical management, since the possibility of nephron sparing technique might still considered in suspected cystic crRCC, but never for cystic clear cell RCC $[10,12]$.

7. Rosenkrantz $A B$, Hindman N, Fitzgerald EF et al: MRI features of renal oncocytoma and chromophobe renal cell carcinoma. Am J Roentgenol, 2010; 195: W421-27

8. Chen S, Jin B, Xu L et al: Cystic renal cell carcinoma: A report of 67 cases including 4 cases with concurrent renal cell carcinoma. BMC Urol, 2014; 14: 87

9. Raman SP, Johnson PT, Allaf ME et al: Chromophobe renal cell carcinoma: Multiphase MDCT enhancement patterns and morphologic features. Am J Roentgenol, 2013; 201: 1268-76

10. Young JR, Margolis D, Sauk S et al: Clear cell renal cell carcinoma: Discrimination from other renal cell carcinoma subtypes and oncocytoma at multiphasic multidetector CT. Radiology, 2013; 267: 444-53

11. Low G, Huang G, Fu W et al: Review of renal cell carcinoma and its common subtypes in radiology. World J Radiol, 2016; 8: 484-500

12. Zhang J, Liu B, Song $N$ et al: Diagnosis and treatment of cystic renal cell carcinoma. World J Surg Oncol, 2013; 11: 158 